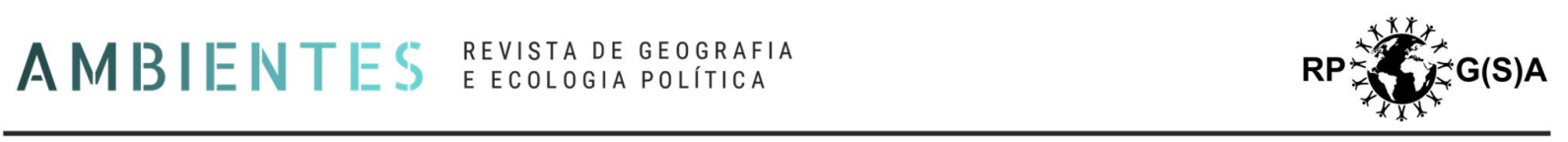

\title{
Resenha
}

\section{Amazônia na encruzilhada}

\author{
Maria Célia Nunes Coelho
}

Amazônia: encruzilhada civilizatória. Tensões territoriais em curso, Carlos Walter Porto-Gonçalves. Rio de Janeiro: Consequência, 20D. 111 pp., ISBN 978-8-56943720-8.

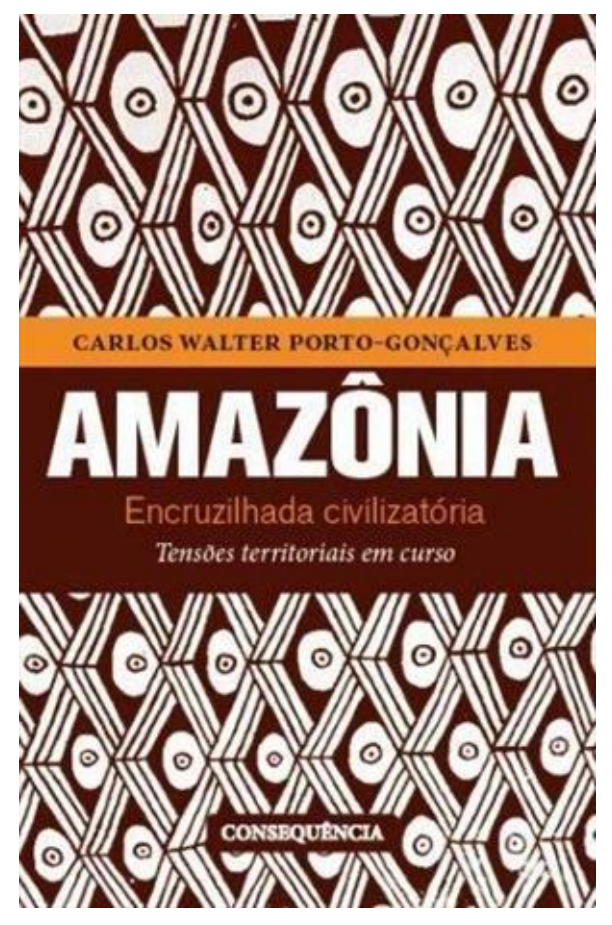

0 crescimento e a expansão populacional e econômica no mundo são indissociáveis das demandas cada vez mais expressivas de matéria e energia, das tentativas de aquecimento da economia e do colapso ambiental em curso, abordados por Carlos Walter Porto-Gonçalves em seu livro Amazônia: encruzilhada civilizatória. E é no contexto, de um lado, dos conhecimentos históricos e da integração das regiões ricas em matérias-primas e energia à "economia-mundo" capitalista (WALLERSTEIN, 1974 e ARRIGHI, 1996) e, de outro, das mudanças climáti- 
cas, que se torna necessário analisar e interpretar a longa história de exploração e ocupação humana da Amazônia e seus efeitos temporais e espaciais.

Nos últimos 50 anos, as relações entre a flora e a fauna, a ocupação humana e econômica e a vida em geral, na Amazônia, sofreram transformações aceleradas. Passado e presente se cruzam e encruzilhadas civilizatórias se sobrepõem. Assim, a região tem sido um lócus de processos de empobrecimento de seu frágil ambiente, urbanização acelerada, extrativismo industrial-exportador, tensões territoriais e ameaças aos povos que lá vivem.

As visões de Amazônia e as alterações sócio-espaciais e físico-ambientais radicais na região são problematizadas como partes importantes das narrativas que enfatizam o colapso socioambiental regional em gestação. 0 problema passa a ser, portanto, a superação do colapso ambiental em progresso. As rápidas transformações metabólicas, pano de fundo da análise, são agravadas pelas forças cósmicas que reconfiguram mudanças climáticas globais que atingem, embora desigualmente, todo o planeta Terra.

Nesse livro, 0 autor traça sua abordagem centrada na análise da interação entre natureza e sociedade, da relação entre espaço e tempo e no exame das escalas constituídas por relações sociais e de poder. Inicia sua narrativa dedicandose, nos primeiros capítulos (1e 2), a criticar as visões acerca da Amazônia e a identificar e examinar o sociometabolismo que muda a região e que cumpre funções de alteração no metabolismo do planeta como um todo. Nos capítulos se- guintes ( 3 , 4 e 5), ele aborda as transformações socioambientais decorrentes das políticas públicas (de cunho moderno: industrial e empresarial) aplicadas à Amazônia, ainda em curso. No capítulo 6, trata dos conflitos e das r-existências (forma usada pelo autor) vividas pelas populações pobres e subalternas, para chegar, no capítulo 7, a discutir a seguinte afirmação e indagação: “Na Amazônia, no passado, havia um futuro. E no presente?"

Para dar conta de sua explanação, o autor lança mão de autores e contribuições de disciplinas diversas. O livro foi basicamente elaborado à luz dos conhecimentos histórico-geológicos da bacia e da floresta amazônica; dos saberes ancestral-históricos dos diferentes grupos, povos, etnias, nacionalidades e classes sociais que vivem ou viveram na região, descritos por arqueólogos, antropólogos, historiadores e geólogos; da visão biogeográfica do geógrafo Aziz Ab'Sáber (defensor da Teoria dos Refúgios) e outros geógrafos, biólogos e geólogos. Ao examinar os megaprojetos, o autor utilizou a denominação do padrão geográfico decorrente deles de "industrialização da selva" (p. 43, em uma referência à publicação do trabalho de P. Litter relativo aos Megaproyectos en la Amazonía, de 2013). 0 autor ainda se inspirou no raciocínio de C. Castoriadis (A instituição imaginária da sociedade, edição brasileira de 1982); na obra de Milton Santos, ou seja, na tese relativa à afirmação do "espaço geográfico como acumulação desigual de tempos"; e na tese de historiador Marc Bloch, referente à " contemporaneidade do não coetâneo" (esses últimos referenciados na página 10); bem como nas 
críticas das id eias e ações coloniais e moderno-coloniais (vide, sobre a colonialidade do saber e do poder, referências a Edgar Lander e Anibal Quijano, na página 18).

Nas palavras de Porto-Gonçalves (p. 9), "[d]estacamos a necessidade de superar (...): (1) a separação natureza-sociedade, (2) a dicotomia espaço-tempo, (3) a visão linear da história (evolucionismo) e (4) o etnocentrismo, ou melhor, a colonialidade do saber e do poder que ainda prevalecem nas análises acerca da região." Esses obstáculos impedem a efetivação das análises dialéticas, coerentes e mais completas ou menos equivocadas sobre a Amazônia pela maioria dos cientistas sociais, jornalistas e outros formadores de opinião.

Expressa no subtítulo do livro, a ideia de encruzilhada civilizatória apresentada pelo autor está associada ao "padrão de poder e de saber fundado na ideia de 'dominação da natureza' (Francis Bacon), a qual se relaciona ao colapso ambiental que vivemos" (p. 11). EncruziIhadas civilizatórias podem ser resultados da aplicação às realidades de outras nações daquelas ideias e daqueles valores das nações até então autopercebidas como civilizadas do mundo ocidental, e que foram apoiadas na dinâmica capitalista de matriz "eeuurocêntrica" (termo utilizado pelo autor).

Os conceitos de metabolismo e de sociometabolismo foram pouco explicitados pelo autor, ${ }^{1}$ que aborda, especificamente, as transformações sociometabólicas que estão em curso na Amazônia, transformações essas que ocorrem de forma mais acelerada desde a segunda metade do século XX.

Porto-Gonçalves opta por uma explanação que difere de alguns tratamentos muito frequentes em escritos sobre a Amazônia, os quais:

1) insistem no "vazio da Amazônia";

2) consideram a história da Amazônia, o mais tardar, a partir da chegada do europeu, ou, especificamente, do Marquês de Pombal (1750-1977), ou a partir do Ciclo da Borracha, no século $X I X$, ou ainda mais recentemente, da segunda metade do século XX;

3) abordam a Amazônia como se ela fosse apenas brasileira;

4) não trabalham as dimensões escalares das problemáticas tratadas;

5) não agregam ideias, noções de escala espacial e temporal, teorias e conceitos a suas análises, e nem tampouco desenvolvem encadeamento lógico e analítico;

6) analisam conflitos sem examinar as contradições neles reveladas, sem estudar as negociações contraditórias e sem destacar a importância das lutas territoriais.

Tal como Porto-Gonçalves, o sociólogo americano Stephen Bunker, um estudioso da Amazônia já falecido, foi também embalado pela luta que implica rejeitar a camisa de força da dicotomia entre sociedade e natureza e por buscar apoios nos trabalhos críticos e engajados da associação entre desenvolvimento e

¿Diferentemente de González de Molina e Toledo (2014). 
progresso. Porto-Gonçalves, especificamente, enriqueceu suas análises, voltando seus olhares para a Amazônia, seus ecossistemas, seus solos e subsolos e seus povos (em geral, pequenos extrativistas das florestas, dos campos naturais e dos campos já desnudados de vegetação original). De maneira similar a Stephen Bunker (1985 e 1994), PortoGonçalves se refere ao ambiente amazônico como ambientalmente frágil e estreitamente sustentado pela combinação clima, solo e floresta. No extrativismo depredatório, certamente, identifica uma das causas do empobrecimento da Amazônia. Isso levou Bunker a dar ao seu livro de 1985 o título de Underdeveloping the Amazon, com o subtítulo Extraction, Unequal Exchange, and the Failure of the Modern State (BUNKER, 1985), e a se referir, em 1994, à Amazônia como um "ambiente frágil" (fragile environment) (BUNKER, 1994).

No que diz respeito aos conceitos utilizados, também, similarmente a Bunker, que se apoiou em GeorgescuRoegen, Porto-Gonçalves fundamenta-se nos conceitos de autopoiesis (MATURANA; VARELA, 1973) e de entropia (Lei da Termodinâmica), refletindo sobre a perda irreversível de energia que não se pode transformar mais em trabalho.

Em seu livro, Carlos Walter PortoGonçalves elaborou um balanço ou síntese da história de longa duração da Amazônia (não restrita à Amazônia brasileira). Todo balanço e toda síntese são feitos segundo pontos de vista científicos e políticos, defendidos pelo autor. Por esse motivo, ele narra uma história da Amazônia que vai da última glaciação à nossa época, adotando a concepção de que os humanos, há 12.000 ou 17.000 anos, se afeiçoaram às florestas agora em processo de transformação/destruição. Nesse balanço ou síntese há visibilidades e invisibilidades.

Alguns reparos, que não alteram 0 valor do trabalho, podem contudo ser feitos, como o não refino da discussão do Ciclo da Borracha que marcou a realidade amazônica. Nota-se, por exemplo, que, ao traçar a história populacional e econômica da Amazônia, a história da borracha foi só rapidamente tratada, perdendo a oportunidade de ressaltar que só nesse período é que o espaço amazônico foi transformado em região econômica (M ACHADO, 1997, p. 22). Parece oportuno lembrar que ouro, borracha, cacau, carne, madeira, ferro, bauxita, cobre, níquel, soja, milho etc. são commodities demandadas pelos países de economias centrais, que comandam as "trocas desiguais" que vigoram no "sistema da economia-mundo capitalista".

A borracha, no passado, e a pecuária, os minérios e os cereais, no presente, modificaram o desenho geográfico ou 0 ambiente físico-social amazônico. A partir da segunda metade do século $X X$, com o modelo extrativo de base empresarialindustrial e exportadora, redes de energia e vias fluviais, terrestres, ferroviárias e dutos (minerodutos, gasodutos etc.), bem como redes de telecomunicações foram construídas, dando origem às superfícies de regulação (PIRES DO RIO; PEIXOTO, 2001) e aos nós de rede que conferiram acessibilidade, população e dinamismo aos espaços por elas (redes) favorecidos.

Desde 1970, as estradas possibilitaram conexões anteriormente inexis- 
tentes. Contemporaneamente, de acordo com planos formulados pela Iniciativa para a Integração da Infraestrutura Regional Sul-Americana (IIRSA), a região vem sendo cortada por eixos formadores de corredores de exportação. Esses corredores podem dar origem apenas às passagens de mercadorias e não efetivamente ao processo de transformar espaços desconectados em regiões ou sub-regiões econômicas interligadas pelos eixos de circulação. A propósito, indagamos: onde estão as relações geográficas ou as expressões espaciais desconstrutivas/construtivas dos "novos objetos técnicos" (estradas, usinas hidrelétricas, portos etc., de acordo com Milton Santos)?...

Em suma, o livro escrito por PortoGonçalves é rico na escolha da temática e nas definições dos problemas de investigação. Nele estão contidos mapas descritivos dos elementos transformadores da realidade. ${ }^{2}$ Ele traz para o leitor um conjunto de capítulos elaborados no âmbito de uma corrente de pensamentos - que balizam as transformações no metabolismo que afetam o ambiente e, consequentemente, a geografia da Amazônia. Com exceção das tensões territoriais, observamos que as expressões espaciais das transformações observadas nos campos e nas cidades (como a emergência/ desaparecimento de cidades, o crescimento/decréscimo de cidades com formações de bairros ou distritos, as mudanças e o redesenho nas redes de cidades etc.) foram pouco exploradas nesse trabalho do autor. 0 mérito ou a riqueza

\footnotetext{
2 Não utilizados pelo autor como fontes de indagações, talvez por fugirem aos seus propósitos iniciais.
}

maior do trabalho está tanto no respeito ao material humano, no raciocínio geográfico, no jogo das interligações escalares, no significado geoeconômico e geopolítico da região e no diálogo interdisciplinar, quanto no exercício de síntese.

Além da linguag em clara e concisa, destaco a erudição do autor e seus conhecimentos acerca dos países da América do Sul. Ressalto ainda sua sensibilidade não só relativa aos povos indígenas, mas também aos demais "povos da floresta", ou seja, ao conjunto de populações de posições subalternas na sociedade e na economia da Amazônia.

Finalmente, recomendo esse livro a leitores especialistas e não especialistas em Amazônia, estudiosos(as) e críti$\cos$ (as) das realidades locais e regionais da América do Sul afetadas por mudanças sociometabólicas. Estas mutações geraram encruzilhadas, resultantes de articulações entre diversas escalas espaciais - locais/regionais/nacionais e subcontinentais - com a escala do mundo, que alteraram relações de poder, sociais, espaciais e culturais, ainda obscuras. Além do mais, a Amazônia reflete os valores ocidentais coloniais e recoloniais, definidores dos destinos dos patrimônios físico-ambientais, humanos e culturais. Segundo o olhar de Porto-Gonçalves, tal visão crítica motivará a imaginação dos leitores/pesquisadores voltados para as interpretações críticas do passado e do presente, bem como para o exame prospectivo do destino da Amazônia. Isso levará pesquisadores, em particular, a tratar de questões como (a) as ligadas aos 
atuais e futuros/probabilísticos contextos globais, continentais, subcontinentais, nacionais e regionais/locais, e (b) as vinculadas às relações entre avanços capitalistas, exploração volumosa dos re- cursos (para atender demandas globais)

e conflitos territoriais/socioambientais à luz de novas matrizes (não coloniais ou neocoloniais) de pensamento.

\section{Referências}

ARRIGHI, G. 0 longo século XX. São Paulo: EDUNESP, 1996.

BUNKER, Stephen G. Underdeveloping the Amazon: Extraction, Unequal Exchange, and the Failure of the Modern State. Chicago e Londres: University of Chicago Press, 1985.

Flimsy joint ventures infragile environments. In: BARHAM, Bradford; BUNKER, Stephen G.; O'HEARN, Dennis (orgs.): States, Firms, and Raw Materials: The World Economy and Ecology of Aluminum. M adison: University of Wisconsin Press, 1994, p. 261-296.

GONZÁLEZ DE MOLINA, Manuel; TOLEDO, Víctor M. The Social Metabolism: A Socioecological Theory of Historical Change. Heidelberg e outros lugares: Springer, 2014.

MACHADO, L. O. O controle intermitente do território amazônico. Território, Rio de Janeiro, $n^{\circ} 2,1997$, p. 19-32.

MATURANA, Humberto; VARELA, Francisco. De máquinas e seres vivos: Autopoiese, a organização do vivo. Porto Alegre: Artes M édicas, 1997.

PIRES DO RIO, G. A.; PEIXOTO, M. N. de Oliveira. Superfície de regulação e conflitos de atribuições na gestão de recursos hídricos. Território, Rio de Janeiro, $\mathrm{n}^{\circ}$ 10, 2001 , p. 51-66.

WALLERSTEIN, Immanuel. The Modern World System: Capitalist Agriculture and the Origin of the European World-economy in the Sixteenth Century. Nova lorque: Academic Press, 1974. 
Maria Célia Nunes Coelho é professora junto ao Programa de Pós-Graduação em Geografia (PPGG) do Departamento de Geografia da Universidade Federal do Rio de J aneiro (UFRJ ) e pesquisadora do CNPq. E-mail: mcncoelho@gmail.com 